\title{
Stabilisation of refraction following extracapsular cataract extraction
}

\author{
P Baranyovits
}

\begin{abstract}
Regular serial refraction was used to determine the rate of stabilisation of refraction following routine extracapsular cataract surgery in 85 eyes. Patients were divided into four groups depending on wound closure technique: limbal section closed by interrupted 8-0 virgin silk, 9-0 polydioxanone or 10-0 nylon sutures, and corneal section closed by continuous 10-0 nylon suture. Stabilisation of refraction, sufficient to prescribe satisfactory glasses, occurred at three months except in the interrupted 10-0 nylon group, when stabilisation was delayed to between four and five months. The factors affecting stabilisation and the causes of the differences observed are discussed.
\end{abstract}

The prescription of 'first glasses' following cataract surgery is usually undertaken after a fixed and often arbitrary period, as frequent serial refractions are not practical in most busy outpatient departments. Glasses prescribed too soon may cause disappointment and unnecessary expense; if prescribed too late they may prolong disability and frustration.

Changes in refraction following cataract surgery have been recognised for over a century. Many workers have investigated postcataract astigmatism. The effects of the following factors have been studied: type, ${ }^{1-4}$ depth, ${ }^{5}$ and number of sutures, pre- or postplaced sutures, ${ }^{6}$ wound
Wolverhampton and Midland Counties Eye Road, Wolverhampto WV3 9QR

P Baranyovits

Correspondence to:

P Baranyovits, FRCS

Accepted for publication 15 March 1990

Figure 1 Rate of change of sphere.

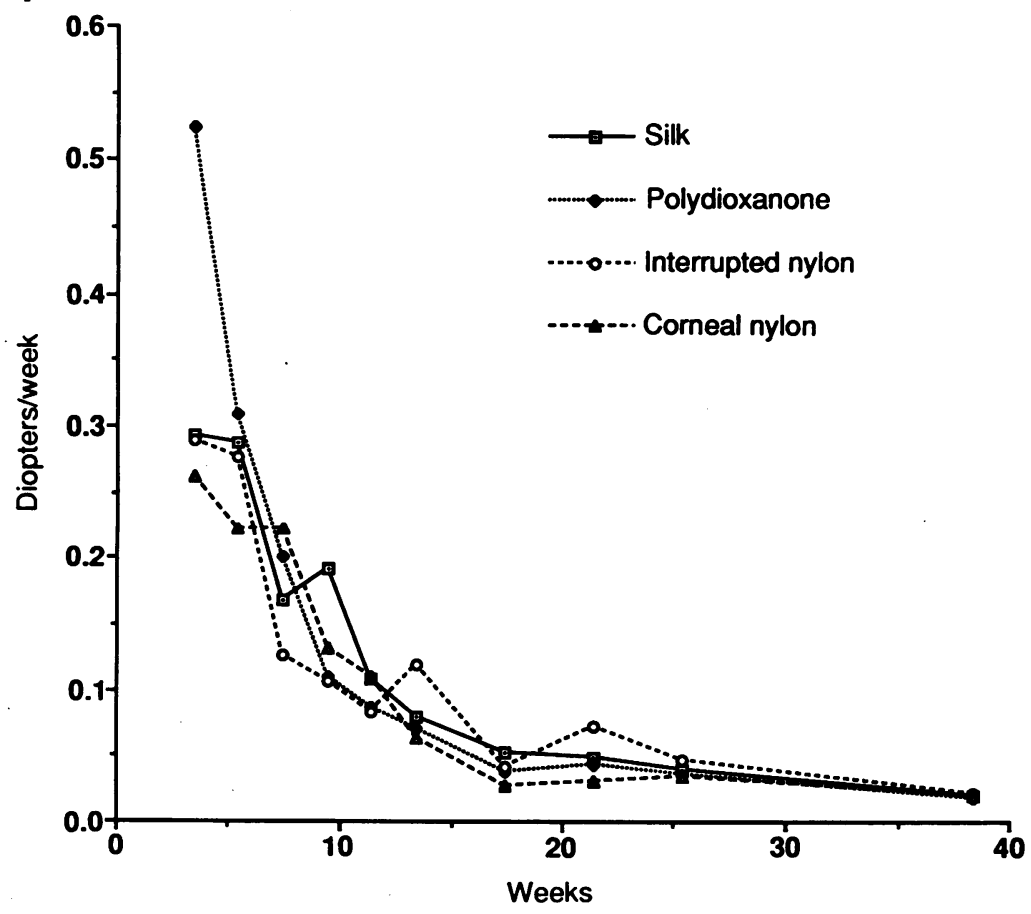

placement, ${ }^{7}$ and size of wound. ${ }^{8}$ More recently techniques of modifying postcataract astigmatism by choice of incision ${ }^{9}$ and suture adjustment ${ }^{10}$ or removal ${ }^{1112}$ have all been considered. Changes of corneal curvature as a function of time have been investigated, but the actual rate of stabilisation of the cataract wound has received less attention.

In 1950 Floyd $^{13}$ reported on 47 eyes following cataract surgery with Graefe section and two sutures. Follow-up by monthly keratometry for six months suggested 'significant' changes in corneal curvature for at least three months after surgery. Gill ${ }^{14}$ in 1972 followed up 1500 postoperative cataract patients; they had intracapsular extractions closed with gut, silk, or nylon, and keratometry was performed at unspecified intervals for up to one year. All groups showed a decay in the initial with-the-rule astigmatism persisting for at least six months. In 1984 Reading $^{8}$ reported on 43 eyes undergoing intracapsular cataract extraction sutured with virgin silk. These patients were followed up at monthly intervals for one year by photokeratometry. Changes in corneal curvature after one month were found to be 'small'.

In 1988 we reported ${ }^{15}$ on 47 eyes following intracapsular cataract extraction at Wolverhampton. Patients were divided into two groups: sections were closed either with interrupted 8-0 virgin silk or continuous 9-0 nylon. Refraction was performed every two weeks for the first three months and then at monthly intervals. The results suggested that stability sufficient to prescribe glasses was achieved at three months in the silk group and four months in the nylon group.

Recently there have been several long-term studies $^{1216}$ in which the period of follow-up extended for up to five years. Extracapsular cataract extraction was performed with a posterior chamber intraocular lens (IOL), and sections were sutured with nylon, polypropylene (Prolene), or polyester (Mersilene). Relatively large numbers of patients were included, but follow-up was at rather infrequent intervals. All groups showed a decay of the initial with-therule astigmatism, which persisted for up to three years. Cravy, ${ }^{4}$ reporting on 395 patients, found 'initial stabilisation' at one month in the 10-0 nylon group but suggested that glasses may need to be changed up to four times in the first year. Axt, ${ }^{16}$ reporting on 500 cases with sections closed by $10-0$ interrupted nylon and continuous $8-0$ polyglactin (Vicryl), found the greatest changes during the first six months and that 'permanent' glasses could be prescribed at between nine and 12 months.

This prospective study was undertaken to monitor refraction changes occurring during the first nine months after the smaller sections of 
extracapsular surgery. The aim was to determine when stability is sufficient to prescribe 'first glasses,' as complete stability may not be achieved for several years after surgery. Other questions considered were whether the rate of stabilisation is consistent in different patients and whether it is influenced by closure technique, age, or the degree of immediate postoperative astigmatism.

\section{Material and methods}

PATIENTS

From the beginning of this prospective study all patients undergoing uncomplicated extracapsular cataract extraction were included provided they were able, co-operative, and had no other serious ocular disease. A total of 81 patients, 81 eyes, were followed up for nine months. The total included 48 women (average age 73.3 years, $95 \%$ confidence interval $2 \cdot 6$ ) and 33 men (average age $67 \cdot 1$ years, $95 \%$ confidence interval 3.0).

\section{SURGERY}

On a consecutive basis patients were divided into four groups: Group A: limbal incision, closure with 5 interrupted 9-0 virgin silk sutures (20 eyes). Group B: limbal incision, closure with 5 interrupted 9-0 polydioxanone (PDS) sutures (20 eyes). Group C: limbal incision, closure with 5 interrupted $10-0$ nylon sutures (20 eyes). Group D: corneal section, closure with continuous $10-0$ nylon suture ( 21 eyes).

Groups A, C, and D were included because they were the three closure techniques commonly used in the Wolverhampton Eye Infirmary and many other hospitals. Group B, interrupted 9-0 polydioxanone sutures (PDS), was included because it is a new type of suture becoming available to the ophthalmologist. Poly-

Figure 2 Rate of change of dioxanone is a synthetic suture material which is

cylinder.

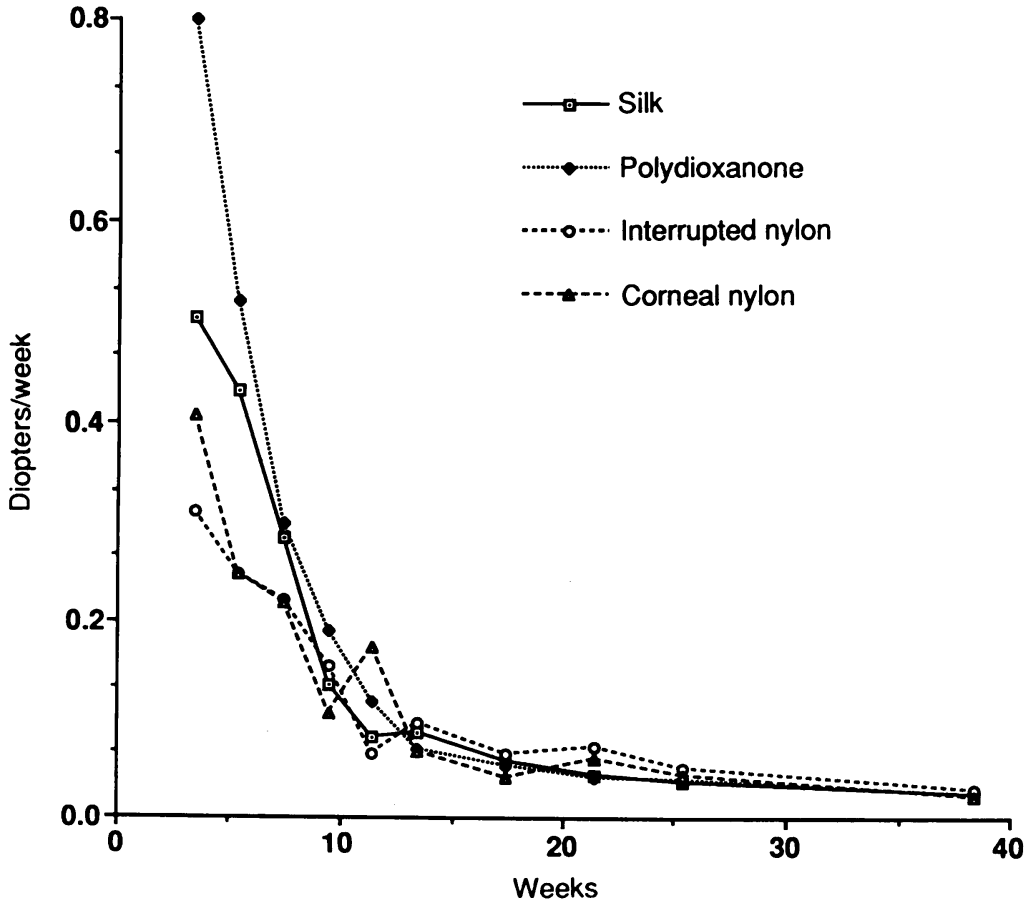

absorbed by hydrolysis; its half life in tissue is 28 days ${ }^{17}$ (that is, loss of half tensile strength). In the 9-0 form polydioxanone is a monofilament. Three different surgeons performed the operations using a similar microsurgical technique. Limbal incisions extended approximately $120^{\circ}$ and corneal sections approximately $140^{\circ}$. Extracapsular cataract extraction was then performed following routine anterior capsulotomy or by intercapsular technique. The nucleus was expressed and remaining cortex aspirated by coaxial cannula. A J-loop posterior chamber lens was then inserted into the capsular bag. Patients were allocated in rotation to the four groups described above. All patients were prescribed a topical steroid (betamethasone $0 \cdot 1 \%$ ) four times a day for three weeks; this was then reduced and discontinued over the following four weeks.

\section{FOLLOW-UP}

All patients were followed up by the author for nine months. Refraction was performed during the first week after surgery and repeated at twoweekly intervals for three months, thereafter monthly for a further three months. The final refraction was performed at nine months. All refractions were carried out with the same equipment, ensuring a constant back vertex distance. Retinoscopy was followed by subjective refraction; the sphere was confirmed by the duochrome test and the cylinder and axis by using Jackson's cross cylinder.

Serial refractions were analysed and stabilisation times were compared over values of the independent variables by means of analysis of variance (ANOVA). In the case of significant relationships linear contrasts were used to identify the source of significance.

\section{Results}

The rate of change of each component of refraction was calculated from the serial refractions of each patient. The units of change were dioptres/ week and degrees/week. The mean rate of change at all time intervals was calculated for each suture group and is presented graphically in Figures 1, 2 and 3.

The 'absorbable' suture virgin silk and polydioxanone showed an initial rapid change in refraction, particularly with the cylinder and axis component. This was associated with the rapid change from with-the-rule astigmatism to against-the-rule occurring at approximately five weeks in both the silk and polydioxanone groups. At nine months $100 \%$ of eyes in the silk group and $91 \%$ of eyes in the polydioxanone group had against-the-rule astigmatism. The decay of the induced with-the-rule astigmatism in the nylon suture groups was more gradual: at nine months $55 \%$ of eyes in the interrupted nylon group and $64 \%$ of eyes in the corneal section group had developed against-the-rule astigmatism. These results are displayed in the Table.

The prescribing time was estimated retrospectively for each patient. For the purposes of this study this was taken to be the time after surgery that the refraction was judged to be sufficiently stable to allow the satisfactory prescription of 
glasses. The refraction results for the full nine months were reviewed, and the prescribing time was taken to be the earliest time that the refraction approached the 'final' nine-month result. The criteria used were fairly strict - a maximum difference of 0.5 dioptre in sphere, 0.25 dioptre in cylinder, and $5^{\circ}$ in axis. The results are displayed in the Table and graphically in Figure 4. The mean prescribing time for groups A, B, and $\mathrm{D}$ is in the region of three months and for group $C$ (interrupted 10-0 nylon) between four and five months. These results are similar to our findings with the larger sections in intracapsular cataract extractions. ${ }^{15}$

Analysis of variance showed a significant difference between the suture groups $(p=0.020)$. The source of significance was the prolonged prescribing time in group $\mathrm{C}(\mathrm{p}=0.003)$. Greater variation in prescribing time was found in both nylon groups ( $C$ and $D)$ than in the absorbable suture groups (A and B). Finally no significant correlation was demonstrated between patient age, initial corneal distortion (initial cylinder), and rate of stabilisation.

\section{Discussion}

All the eyes included in this study showed a decay of surgically induced with-the-rule astigmatism. This process is well recognised and described in many other studies. ${ }^{4121819}$ Recent long-term studies have shown that this astigmatism decay may continue for two to three years before complete stabilisation of the cataract wound.

The major influence in this characteristic change in astigmatism is the complex relationship between suture and wound healing. Relaxation of the tissue, compressed by sutures along the incision, occurs owing to a loss of tensile strength in the suture, loosening of knots, or the suture cutting through the tissue. This may restore the preoperative corneal curvature, though the relaxation of tissue across the wound does not necessarily coincide with the wound's achieving strength sufficient to prevent its stretching. Significant wound stretching may continue the process of decay of induced astigmatism beyond the preoperative corneal curvature resulting in against-the-rule astigmatism.

The speed of wound healing in the cornea and limbal area is very slow. In 1969 Flaxel and

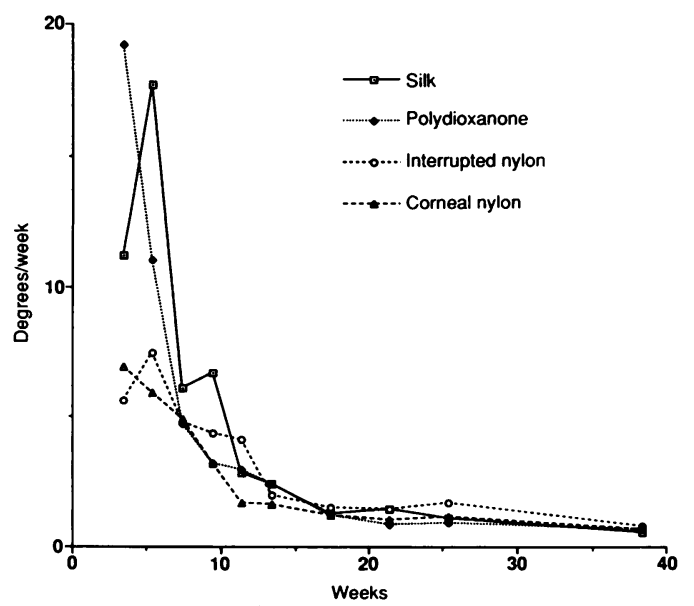

Swan ${ }^{20}$ reported on 18 post-mortem eyes obtained at varying times after cataract surgery. They found that initial fibrovascular invasion of the wound was complete at two weeks, but this provided very little strength. The increase in strength of the limbal wound depends on the restoration of the collagen structure. Wound remodelling was first seen in a 46-day specimen and was complete by 2.5 years. In 1968 Gassel and Dohlman ${ }^{21}$ reported on the tensile strength of limbal and corneal wounds in rabbits. Again healing was found to be very slow.

The absorbable suture polydioxanone and virgin silk, which behaves in a similar manner, lose their apparent tensile strength at between five and six weeks. This can be seen as a rapid change in astigmatism in Figures 2 and 3. After this period there is a more gradual decay of surgically induced with-the-rule astigmatism, and most of the sutures, particularly polydioxanone, are absorbed or extruded by six months. This being the case, suture tension is soon lost as a factor influencing the stabilisation of refraction in groups A and B. Hence, wound strength remains as the only major variable in this simplified equation. One would then expect that eyes sutured with an absorbable material would stabilise at a rate directly related to wound healing and therefore more quickly and consistently, because there are no prolonged influences on the wound. The results from this study support this, though the difference in prescribing time between the absorbable suture groups and the corneal continuous nylon group was not significant. The degree of variation in the mean prescribing times of both absorbable sutures (A and $B$ ) were less than the nylon groups (C and D).

The corneal section group, sutured with continuous nylon, had a mean prescribing time only slightly longer than the absorbable suture groups but significantly less than the limbal interrupted nylon group. It is unlikely that the position of the section (limbal versus corneal) contributes much to this difference, as a similar difference exists between suture groups $A$ and $B$ and group $C$ (all limbal sections). Moreover the rate of wound healing can be expected to be similar, if not greater, in the more peripheral wound. ${ }^{21}$ The remaining difference between groups $C$ and $D$ is the suture technique (continuous versus interrupted nylon). By virtue of the interconnecting segments of suture in the continuous group the tension in each 'bite' will show less variation than the individual sutures in the interrupted group. Hence the loss of tension that occurs in a continuous suture postoperatively should allow decay in the induced surgical astigmatism with a more stable axis. Loosening of an interrupted non-absorbable suture is likely to be unrelated to its neighbours, resulting in erratic shifts of axis. Figure 3, showing rate of change of axis, appears to support this view, while Figures 1 and 2 showing rate of change of sphere and cylinder, are more similar.

An ideal suture for conventional cataract surgery would maintain its tensile strength long enough to allow the healing wound to reach sufficient strength to prevent significant stretching when unsupported. This should be in the 
Table 1 Refraction results for each wound closure group

\begin{tabular}{|c|c|c|c|c|}
\hline $\begin{array}{l}95 \% \text { Confidence interval } \\
\text { in brackets }\end{array}$ & $\begin{array}{l}\text { Group } A \\
(\text { silk })\end{array}$ & $\begin{array}{l}\text { Group B } \\
(P D S)\end{array}$ & $\begin{array}{l}\text { Group } C \\
\text { (interrupted } \\
\text { nylon) }\end{array}$ & $\begin{array}{l}\text { Group D } \\
\text { (corneal } \\
\text { nylon) }\end{array}$ \\
\hline $\begin{array}{l}\text { Number of eyes } \\
\text { Mean initial cyl }\end{array}$ & $\begin{array}{l}21 \\
2 \cdot 64 \mathrm{D} \\
(0 \cdot 49)\end{array}$ & $\begin{array}{l}22 \\
2 \cdot 74 \mathrm{D} \\
(0.53)\end{array}$ & $\begin{array}{l}20 \\
2.99 \mathrm{D} \\
(0.49)\end{array}$ & $\begin{array}{l}22 \\
2.65 \mathrm{D} \\
(0.64)\end{array}$ \\
\hline $\begin{array}{l}\text { \%With-the-rule } \\
\text { Mean final cyl }\end{array}$ & $\begin{array}{l}95 \% \\
2.45 \mathrm{D} \\
(0.39)\end{array}$ & $\begin{array}{l}100 \% \\
2 \cdot 11 \mathrm{D} \\
(0 \cdot 44)\end{array}$ & $\begin{array}{l}100 \% \\
1.9 \mathrm{D} \\
(0 \cdot 34)\end{array}$ & $\begin{array}{l}82 \% \\
2 \cdot 03 \mathrm{D} \\
(0.38)\end{array}$ \\
\hline $\begin{array}{l}\text { \%Against-the-rule } \\
\text { Nine-month decay of surgically } \\
\text { induced astigmatism } \\
\text { Mean prescribing time }\end{array}$ & $\begin{array}{l}100 \% \\
5 \cdot 07 \mathrm{D} \\
(0 \cdot 74) \\
12 \cdot 9 \mathrm{wks} \\
(2 \cdot 5)\end{array}$ & $\begin{array}{l}91 \% \\
4 \cdot 72 \mathrm{D} \\
(0 \cdot 49) \\
13 \cdot 4 \text { wks } \\
(2 \cdot 2)\end{array}$ & $\begin{array}{l}55 \% \\
3 \cdot 24 \mathrm{D} \\
(0 \cdot 89) \\
18.7 \mathrm{wks} \\
(2 \cdot 9)\end{array}$ & $\begin{array}{l}64 \% \\
2 \cdot 84 \mathrm{D} \\
(0 \cdot 89) \\
14 \cdot 6 \text { wks } \\
(3 \cdot 0)\end{array}$ \\
\hline
\end{tabular}
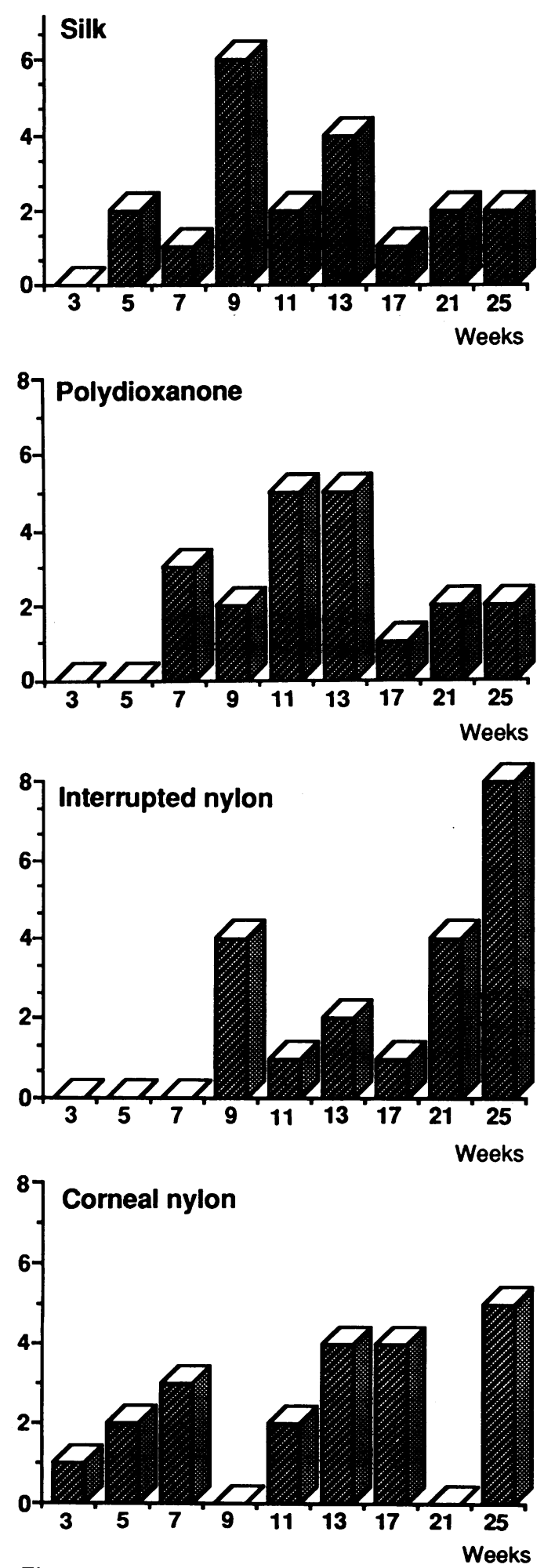

Figure 4 Graphs showing when patients reach stable refraction following extracapsular cataract extraction in each wound closure group. region of 12 to 14 weeks, which is the mean stabilisation time range for polydioxanone and silk groups (in effect by this time these wounds are unsupported). The ideal suture should then be absorbed to avoid further influencing wound stabilisation. An alternative solution would be to use a non-absorbable material and remove or cut all sutures at a similar time. The rate of wound healing is the key to stabilisation. Hence procedures that may delay this process should also be avoided, such as excessive cautery and prolonged use of steroids.

Recent studies ${ }^{412}$ have shown that complete stabilisation of refraction does not occur until two to three years after cataract surgery. As one would not expect patients to wait this long for their first glasses, they should be prescribed when the rate of refraction change is considered slow enough to be acceptable. For the purposes of this study the prescribing time was calculated by rigid criteria in order to demonstrate differences between suture groups and the degree of variability. In practice this prescribing time, which is no more than a mean for a particular surgical technique, should be used only as a guide. Not only does it show considerable variability but there are several other factors to consider with the individual patient. These would include vision in the fellow eye, potential vision in the operated eye, degree of refractive error, urgency of rehabilitation, and the patient's wishes. However, with better understanding of the behaviour of post-cataract refraction, these many factors may be weighted appropriately when judging when to prescribe 'first glasses.'

1 Pearce JL. Discussion on suture material. Adv Ophthalmol $1970 ; 22: 58-9$.

2 Wyman GJ. Comparison of results: 100 cases with 8-0 silk versus 100 cases with 9-0-10-0 nylon. In: Emery JM, Paton D, eds. Current concepts in cataract surgery. St Louis: Mosby, 1974: $91-2$

3 Stainer GA, Binder PS, Parker WT, Perl T. The natural and modified course of post-cataract astigmatism. Ophthalmic Surg 1982; 13: 822-7.

4 Cravy TV. Long-term corneal astigmatism related to selected elastic, monofilament, nonabsorbable sutures. 7 Cataract Refract Surg, 1989; 15: 61-9.

5 Van Rij G, Waring GO. Changes in corneal curvature induced by sutures and incisions. Am f Ophthalmol 1984; 98: 773-83.

6 Singh D, Kumar K. Keratometric changes after cataract extraction. BrF Ophthalmol 1976; 98: 638-41.

7 Thrasher BH, Boemer CF. Control of astigmatism by wound placement. $\mathcal{F}$ Am Intraocul Implant Soc 1984; 10: 176-80.

8 Reading VM. Astigmatism following cataract surgery. $B$ f Ophthalmol 1984; 68: 97-104.

9 Maloney WF, Grindle L, Sanders D, Pearcy D. Astigmatism control for the cateract surgeon: A comprehensive review of surgically tailored astigmatism reduction. $\mathcal{F}$ Cataract Refract Surg 1989; 15: 45-54.

10 Atkins AD, Roper-Hall MJ. Control of postoperative astigmatism. Br F Ophthalmol 1985; 69: 348-51.

11 Kronish JW, Forster RK. Control of corneal astigmatism following cataract extraction by selective suture cutting. Arch Ophthalmol 1987; 105: 1650-5.

12 Richards SC, Brodstein RS, Richards WL, Olson RJ, Combe $\mathrm{PH}$, Crowell KE. Long-term course of surgically induced astigmatism. F Cataract Refract Surg 1988; 14: 270-6.

13 Floyd G. Changes in corneal curvature following cataract extraction. Am f Ophthalmol 1951; 34: 1525-33.

14 Gills JP. The effect of cataract sutures on postoperative astigmatism. Am F Optom Physiol Opt 1974; 51: 97-100.

15 Baranyovits PR. Stabilisation of refraction following cataract surgery. Brf Ophthmol 1988; 72: 815-9.

6 Axt JC. Longitudinal study of postoperative astigmatism. f Cataract Refract Surg 1987; 13: 381-8.

17 Batholomew RS. PDS (polydioxanone suture): a new synthetic absorbable suture in cataract surgery. Ophthalmologica 1981; 183: 81-5.

18 Cory CC. Prevention and treatment of postimplantation astigmatism. 7 Cataract Refract Surg 1989; 15: 58-60.

19 Jampel HD, Thompson JR, Baker CC, Stark WJ. A computerised analysis of astigmatism after cataract surgery.
Ophthalmic Surg 19:6; 17: 786-90.

20 Flaxel JT, Swan KC Limil extraction. Arch Ophthalmol 1969; 81: 653-9.

21 Gasset AR, Dohlman CH. The tensile strength of corneal wounds. Arch Ophthalmol 1968; 79: 595-602. 